\title{
Reduction of Magnetite in the Presence of Activated Carbon Using Mechanical Alloying
}

\author{
Ledwaba Harry Moloto, ${ }^{1,2}$ Sunnyboy Stanley Manzini, ${ }^{2}$ and Ezekiel Dixon Dikio ${ }^{1}$ \\ ${ }^{1}$ Applied Chemistry and Nanoscience Laboratory, Department of Chemistry, Vaal University of Technology, P.O. Box X021, \\ Vanderbijlpark 1900, South Africa \\ ${ }^{2}$ Material Science Department, Sasol Technology, Sasolburg, South Africa
}

Correspondence should be addressed to Ezekiel Dixon Dikio; ezekield@vut.ac.za

Received 14 February 2013; Revised 14 April 2013; Accepted 22 April 2013

Academic Editor: Svetlana Ibric

Copyright (C) 2013 Ledwaba Harry Moloto et al. This is an open access article distributed under the Creative Commons Attribution License, which permits unrestricted use, distribution, and reproduction in any medium, provided the original work is properly cited.

The reduction behaviour of magnetite using graphite under ball-milling conditions (using a planetary mono mill, Fritsch Pulverisette 6) has been investigated. The reaction of magnetite and graphite at different milling conditions leads to the formation of $\mathrm{Fe}^{2+}$ and $\mathrm{Fe}^{3+}$ species, the former increasing at the expense of $\mathrm{Fe}_{3} \mathrm{O}_{4} \cdot \mathrm{Fe}_{3} \mathrm{O}_{4}$ completely disappeared after a ball to powder ratio of $50: 1$ and beyond. The $\mathrm{Fe}^{2+}$ species were confirmed to be due to $\mathrm{FeO}$ using Mössbauer Spectroscopy and X-ray diffraction techniques. Scanning electron microscopy and transmission electron microscopy analyses confirm the reduction of magnetite to wüstite.

\section{Introduction}

Many oxidic iron compounds (iron oxides: oxy-hydroxides and hydroxides) not only play an important role in a variety of disciplines but also serve as model systems of reduction and catalytic reactions [1]. The reduction of these compounds has been investigated for decades. Despite this, the reduction behaviour of the oxides is not fully understood as yet. To date the reduction mechanism is still plagued with uncertainties and conflicting theories, partly due to the complex nature of these oxides and intermediates formed during the reduction [2].

The reduction of iron oxide occurs in steps. For example, during the reduction of hematite $\left(\alpha-\mathrm{Fe}_{2} \mathrm{O}_{3}\right)$, magnetite $\left(\mathrm{Fe}_{3} \mathrm{O}_{4}\right)$ is first formed followed by nonstoichiometric wüstite $\left(\mathrm{Fe}_{x} \mathrm{O}\right)$ and lastly metallic iron $(\alpha-\mathrm{Fe})$. The rate of transformation depends on the reduction conditions employed (like the reducing agent used such as $\mathrm{H}_{2}, \mathrm{CO}$ or a combination thereof). Further, this reduction is accompanied by changes in the crystal structure as new materials are formed [3].

Direct reduction of iron oxides by solid carbon has also been reported [2]. The carbon source could be coke, graphite, coal, char, deposited carbon, and activated carbon $[2,3]$.
There is still, however, no conclusive mechanistic investigation as to how such transformation occurs. Mechanical alloying is a well-established method used to induce solid state reactions. For example, it has been shown that different iron carbides species can be formed during the ball milling of $\alpha$-Fe with activated carbon at various stages of the process $[4,5]$.

This study reports on the reduction of magnetite using graphite under ball-milling conditions. Magnetite is a naturally occurring iron oxide, which is thermodynamically stable at ambient conditions [6,7]. Therefore magnetite is well suited for the investigation of the reduction behaviour of iron oxides. The effect of ball to powder ratio (BPR), milling time and speed on the reduction process was investigated. The aim of the study is to gain an understanding of the mechanism of the reduction of magnetite induced by graphite during mechanical alloying.

\section{Experimental}

2.1. Materials and Method. Magnetite (Sigma-Aldrich, 98.0\%) and graphite (C) (Sigma-Aldrich, $<20 \mu \mathrm{m}$, synthetic) were weighed to obtain a metal oxide to $\mathrm{C}$ mole ratio of $1: 3$. 
TABLE 1: $\mathrm{F}_{3} \mathrm{O}_{4} / \mathrm{C}(1: 3$ mole ratio) milling conditions.

\begin{tabular}{lcc}
\hline BPR & Time $(\mathrm{h})$ & Speed (rpm) \\
\hline 20 & & \\
30 & 15 & 400 \\
50 & & \\
60 & & 400 \\
100 & & 450 \\
40 & 15 & 500 \\
\hline
\end{tabular}

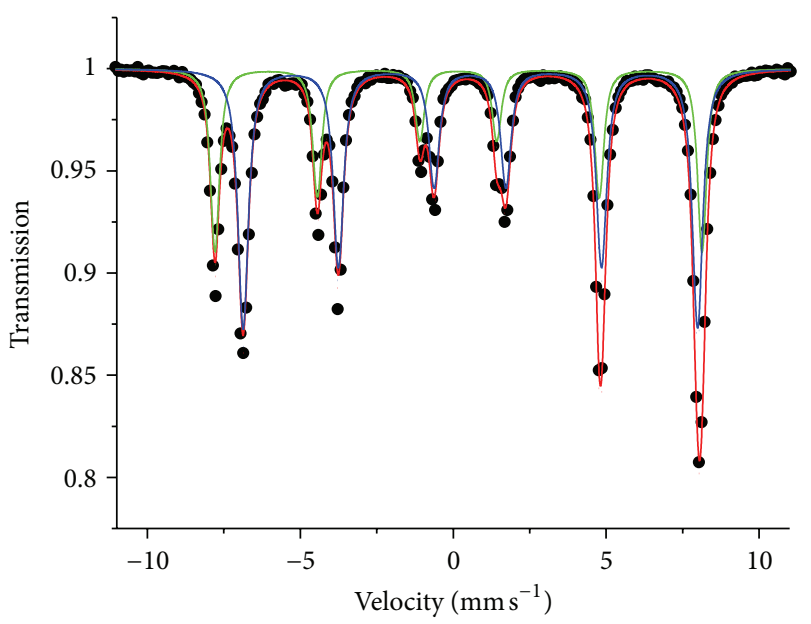

FIGURE 1: Room temperature MAS spectrum of commercial sourced magnetite.

The cumulative mass of the mixture was $20.0 \mathrm{~g}$. The mixture was then placed inside a bowl of a high energy planetary mono mill (Fritsch Pulverisette 6) operating at speeds up to $400 \mathrm{rpm}$. Stainless steel balls were then weighed to get the required ball to powder ratio (BPR) and also placed into the bowl. The BPR ratios of $20: 1$ to $100: 1$ were used. The steel balls used were a mixture of $10 \mathrm{~mm}$ and $20 \mathrm{~mm}$ in diameter, with most of the space taken up by the smaller balls $(10 \mathrm{~mm})$. The speed of the mill was set at $400 \mathrm{rpm}$ and intermittent cooling was achieved by introducing a rest period of 30 minutes for every 30 minutes of milling until the preset milling period of $20 \mathrm{~h}$ was attained. This was done to prevent excessive temperature rise during milling. Although the bowl was sealed in an argon atmosphere, the sealing was insufficient to prevent gas exchange such that the introduction of air into the system could not be ruled out. Once the required milling time had elapsed, the system was allowed to cool back to room temperature and the reaction mixture was then collected for further analysis.

2.2. Characterization. The phase composition and morphological features of magnetite and subsequent reactive products were analyzed by Mössbauer Absorption Spectroscopy (MAS), Field Emission Scanning Electron microscopy (FESEM), High Resolution Transmission Electron microscopy
TABLE 2: MAS parameters of the ball-milled magnetite and graphite mixtures (1:3 mole ratio) at different ball to powder ratios (BPR), while rotational speed and milling periods were kept constant at $400 \mathrm{rpm}$ and 20 hours, respectively.

\begin{tabular}{|c|c|c|c|c|c|}
\hline \multirow{2}{*}{ BPR } & \multicolumn{3}{|c|}{ MAS parameters } & \multirow{2}{*}{-\% Content } & \multirow{2}{*}{ Phases } \\
\hline & ${ }^{\#} \delta / \mathrm{mms}^{-1}$ & ${ }^{\#} \Delta E_{\mathrm{Q}} / \mathrm{mms}^{-1}$ & ${ }^{*} B_{\mathrm{hf}} / \mathrm{T}$ & & \\
\hline \multirow{2}{*}{0} & 0.29 & 0.01 & 49.2 & \multirow{2}{*}{100} & \multirow{2}{*}{$\mathrm{Fe}_{3} \mathrm{O}_{4}$} \\
\hline & 0.66 & 0.01 & 46.0 & & \\
\hline \multirow{4}{*}{$20: 1$} & 0.29 & 0.01 & 48.5 & \multirow{2}{*}{90} & \multirow{2}{*}{$\mathrm{Fe}_{3} \mathrm{O}_{4}$} \\
\hline & 0.61 & -0.01 & 45.1 & & \\
\hline & 0.35 & 1.42 & - & 5 & $\mathrm{Fe}^{3+}$ \\
\hline & 0.77 & 1.38 & - & 5 & $\mathrm{Fe}^{2+}$ \\
\hline \multirow{4}{*}{$30: 1$} & 0.29 & 0.02 & 48.4 & \multirow{2}{*}{42} & \multirow{2}{*}{$\mathrm{Fe}_{3} \mathrm{O}_{4}$} \\
\hline & 0.63 & -0.05 & 45.0 & & \\
\hline & 0.27 & 0.38 & - & 6 & $\mathrm{Fe}^{3+}$ \\
\hline & 0.89 & 0.96 & - & 52 & $\mathrm{Fe}^{2+}$ \\
\hline \multirow{4}{*}{$40: 1$} & 0.28 & 0.02 & 48.4 & \multirow{2}{*}{16} & \multirow{2}{*}{$\mathrm{Fe}_{3} \mathrm{O}_{4}$} \\
\hline & 0.68 & -0.05 & 45.0 & & \\
\hline & 0.28 & 0.44 & - & 11 & $\mathrm{Fe}^{3+}$ \\
\hline & 0.89 & 0.92 & - & 73 & $\mathrm{Fe}^{2+}$ \\
\hline \multirow{2}{*}{$50: 1$} & 0.28 & 0.44 & - & 11 & $\mathrm{Fe}^{3+}$ \\
\hline & 0.89 & 0.92 & - & 89 & $\mathrm{Fe}^{2+}$ \\
\hline \multirow{2}{*}{$60: 1$} & 0.28 & 0.44 & - & 12 & $\mathrm{Fe}^{3+}$ \\
\hline & 0.89 & 0.92 & - & 88 & $\mathrm{Fe}^{2+}$ \\
\hline
\end{tabular}

(HR-TEM), Energy Dispersive Spectroscopy (EDS), and Xray Diffraction Spectroscopy (XRD). The surface morphology (SEM and EDS measurements) were recorded with a JEOL $7500 \mathrm{~F}$ field emission scanning electron microscope. The HR-TEM images of the sample were obtained using a CM 200 electron microscope operated at $100 \mathrm{kV}$. X-ray powder diffraction data acquisition was performed using a Philips X'Pert Pro multi-purpose diffractometer with Fe filtered Co $\mathrm{K} \alpha$ radiation as a primary X-ray beam $(\mathrm{K} \alpha=1.78897 \AA$ ). The instrument was operated at a voltage of $40 \mathrm{kV}$ and tube current of $40 \mathrm{~mA}$ with a goniometer scanning continuously $2 \theta$ values from $5^{\circ}$ to $120^{\circ}$. Phase identification was done using the X'Pert High Score Plus software. MAS measurements were performed using a constant acceleration spectrometer equipped with a ${ }^{57} \mathrm{Co}(\mathrm{Rh})$ source. Mössbauer measurements were recorded at room temperature over a velocity range of $\pm 12 \mathrm{~mm} / \mathrm{s}$. The generated MAS spectra were analyzed by means of a least squares program "Normos" that models the peaks as a combination of quadruple doublets and sextets based on a Lorentzian line-shape profile. The calibration of the velocity scale was done using metallic iron foil $(\alpha-\mathrm{Fe})$. A Zeiss ULTRA 55 FEGSEM Instrument was used for Back scatter electron (BSE) analysis. The instrument has a field emission tungsten hairpin filament with a $\mathrm{ZrO}$ reserve, as an electron source. EDS analysis and elemental mapping were performed using a Bruker XFlash SDD detector that is, controlled by Bruker ESPIRIT software. 

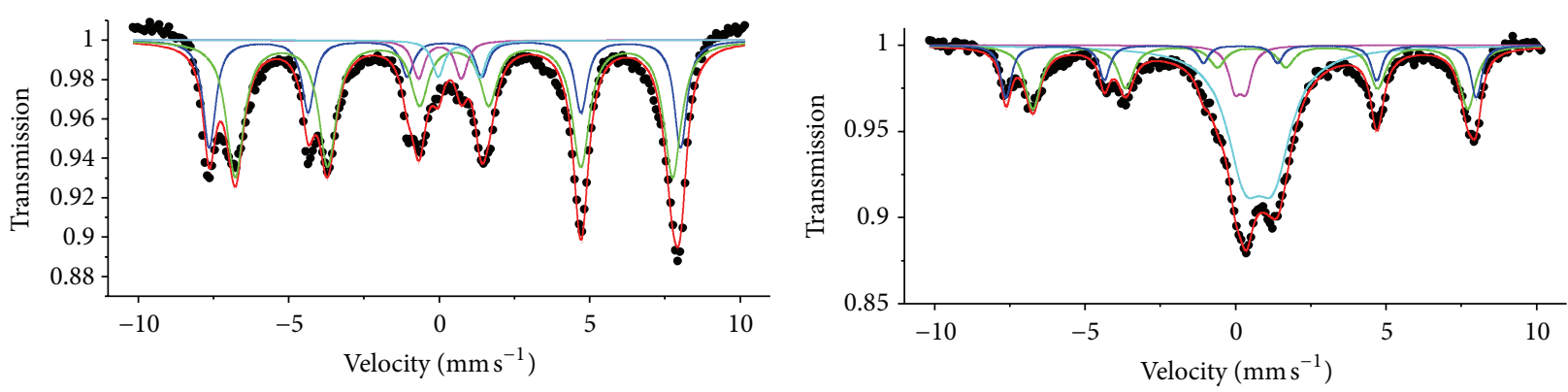

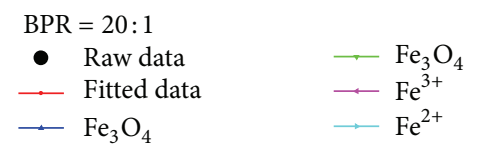

(a)

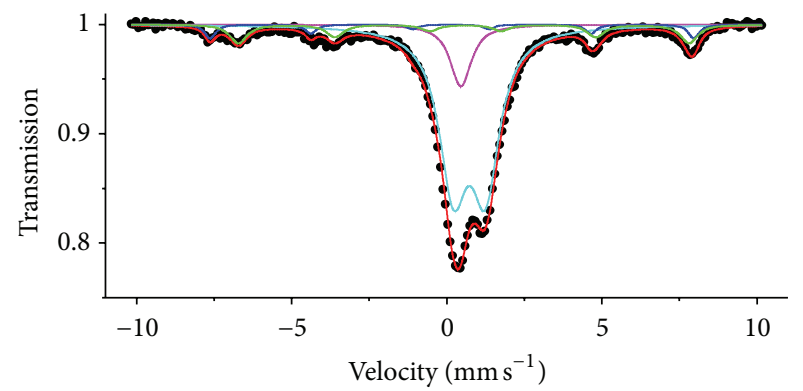

$\mathrm{BPR}=30: 1$
- Raw data Fitted data
- - $\mathrm{Fe}^{3+}$
$-\because \mathrm{Fe}^{2+}$
$--\mathrm{Fe}_{3} \mathrm{O}_{4}$ $-\backsim \mathrm{Fe}_{3} \mathrm{O}_{4}$

(b)

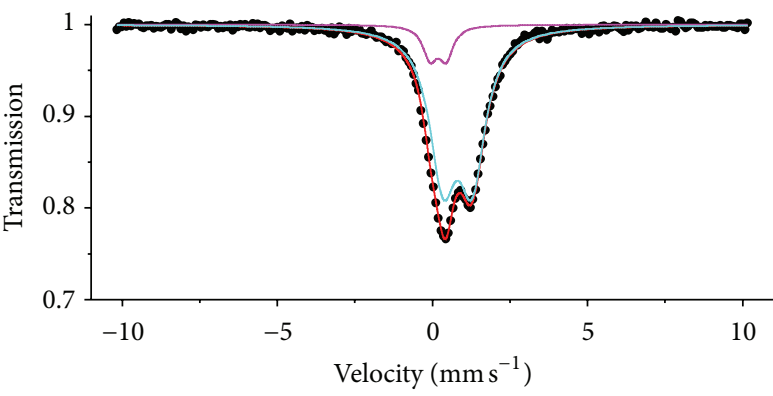

$\mathrm{BPR}=50: 1$

- Raw data

- Fitted data

(d)

(c)

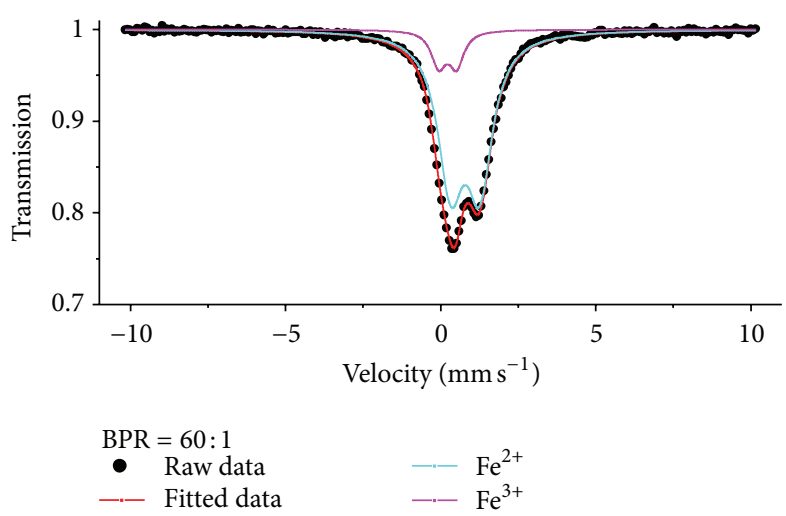

(e)

FiguRE 2: Room temperature MAS spectra of the ball-milled magnetite and graphite mixtures (1:3 mole ratio) at different ball to powder ratios (BPR), while rotational speed and milling periods were kept constant at $400 \mathrm{rpm}$ and 20 hours, respectively.

\section{Results and Discussion}

Ball milling of $\mathrm{Fe}_{3} \mathrm{O}_{4}$ and graphite was performed by varying the BPR whilst keeping the milling period and milling speed constant (Table 1). The as-prepared samples of $\mathrm{Fe}_{3} \mathrm{O}_{4}$ obtained at different milling speeds were collected and analysed to determine the effect of BPR on the morphology and reactive products of the magnetite-graphite mixture. The Mössbauer parameters are presented in Table 2. Figure 1 exhibits the Mössbauer spectrum of commercial magnetite obtained from Sigma-Aldrich, whereas Figure 2 displays the Mössbauer spectra of magnetite-graphite mixture (1:3 mole ratio) at different ball to powder ratios $(20: 1$ to $100: 1)$ and their corresponding X-ray diffractograms are displayed in Figure 3. The spectrum in Figure 1 was fitted with a combination of two sextets with parameters $\delta=0.29 \mathrm{~mm} / \mathrm{s}$, $\Delta E_{\mathrm{Q}}=0.01 \mathrm{~mm} / \mathrm{s}, B_{\mathrm{hf}}=49.2 \mathrm{~T}$ for the outermost sextet and $\delta=0.66 \mathrm{~mm} / \mathrm{s}, \Delta E_{\mathrm{Q}}=0.01 \mathrm{~mm} / \mathrm{s}, B_{\mathrm{hf}}=46.0 \mathrm{~T}$ for the 


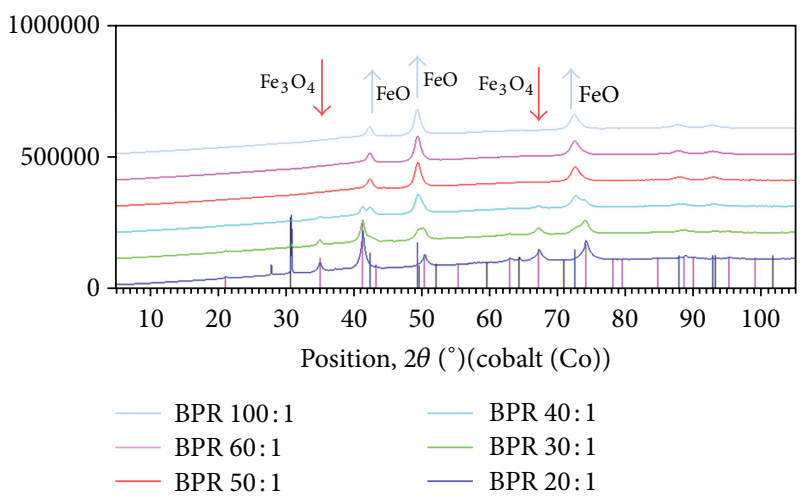

FIGURE 3: X-ray diffractograms of the ball-milled magnetite and graphite mixtures (1:3 mole ratio) at different ball to powder ratios (BPR), while rotational speed and milling periods were kept constant at $400 \mathrm{rpm}$ and 20 hours, respectively.

inner sextet. It has been reported that magnetite presents a ferrimagnetic ordering below the Néel temperature $\left(T_{N}\right)$ of $=850 \mathrm{~K}$ [8], and thus, the MAS spectrum of $\mathrm{Fe}_{3} \mathrm{O}_{4}$ at room temperature consists of two sextets, one corresponding to $\mathrm{Fe}^{3+}$ on the A site (outer sextet) and the other one to a mixture of $\mathrm{Fe}^{2+}$ and $\mathrm{Fe}^{3+}$ on the $\mathrm{B}$ site (inner sextet). Magnetite is an inverse spinel; that is, it has $8 \mathrm{Fe}^{3+}$ cations in a tetrahedral site (A sublattice) with $4 \mathrm{O}^{2-}$ anions, while $8 \mathrm{Fe}^{3+}$ and $8 \mathrm{Fe}^{2+}$ cations are in octahedral site (B sublattice) with $6 \mathrm{O}^{2-}$ anions $[8,9]$. Hence, the structural formulais $\mathrm{Fe}^{3+}\left[\mathrm{Fe}^{2+} \mathrm{Fe}^{3+}\right] \mathrm{O}_{4}$. In typical spinels, the larger cation, like $\mathrm{Fe}^{2+}$ in this example, should have been in the A sublattice. The ratio of $\mathrm{Fe}$ cations on $\mathrm{A}$ site and $\mathrm{B}$ site as well as $\mathrm{Fe}^{3+} / \mathrm{Fe}^{2+}$ ratio for a given sample provides an indication of stoichiometry. For the pure magnetite analysed, the $\mathrm{Fe}$ (A-site)/Fe (B-site) ratio was found to be $1: 2$, while the $\mathrm{Fe}^{3+} / \mathrm{Fe}^{2+}$ ratio was $2: 1$ as expected [10].

The spectrum in Figure 2(a) was obtained when magnetite and graphite mixture was subjected to reactive milling at BPR 20:1. The figure shows two pronounced sextets with parameters matching those of magnetite (and its relative content was about 90\%) coexisting with two quadrupole doublets: the first is due to $\mathrm{Fe}^{3+}$ species with parameters, $\delta=0.35 \mathrm{~mm} / \mathrm{s}, \Delta E_{\mathrm{Q}}=1.42 \mathrm{~mm} / \mathrm{s}$ and a relative content of about $5 \%$. The second doublet was due to $\mathrm{Fe}^{2+}$ species and had parameters $\delta=0.77 \mathrm{~mm} / \mathrm{s}, \Delta E_{Q}=1.38 \mathrm{~mm} / \mathrm{s}$, with a relative content of about $5 \%$. XRD data only exhibited intensity peaks for the magnetite phase; hence the doublets observed using MAS could have been due to small crystallites of magnetite that exhibited superparamagnetism at room temperature or due to phases that were XRD amorphous. The former is most likely to have been the case, and the use of low temperature MAS could have given a definitive answer. Superparamagnetism can be observed when fast relaxations of the magnetic moments due to thermal excitation at temperatures below the Curie temperature or Néel temperature (at which materials are supposed to show magnetic behaviours) occur and usually result in materials exhibiting paramagnetic behaviours [11]. The net effect of such phenomenon on the MAS spectrum is a collapse of the magnetically split components (sextets) into paramagnetic doublets or singlets. Note that superparamagnetism could also be observed if isomorphous substitution of iron by other elements takes place [11], and in this investigation, no such cations were present.

The spectrum is obtained at BPR $30: 1$. Figure 2(b) shows two sextets and two quadrupole doublets as well. The sextets had parameters synonymous with magnetite and its relative content was $42 \%$. The relative contents of $\mathrm{Fe}^{3+}$ and $\mathrm{Fe}^{2+}$ species were 6 and $52 \%$, respectively. The high $\mathrm{Fe}^{2+}$ content undeniably signifyies that the magnetite $\left(\mathrm{Fe}_{3} \mathrm{O}_{4}\right)$ was reduced to a predominantly $\mathrm{Fe}^{2+}$ species. The MAS parameters for the $\mathrm{Fe}^{2+}$ species were markedly different to those obtained at BPR $20: 1$, indicating the possibility that a different $\mathrm{Fe}^{2+}$ species could have been formed in the process. XRD data (Figure 3) indeed showed the presence of wüstite $\left(\mathrm{Fe}_{x} \mathrm{O}\right.$, $0.92 \leq x \leq 0.98$ ), a nonstoichiometric iron oxide which has an iron oxidation state of nearly 2 [12]. The marked decrease in the relative content of the magnetite demonstrated that the use of higher BPR could promote the reduction of magnetite. Indeed at a BPR $40: 1$, Figure 2(c), the relative content of magnetite receded further to about $16 \%$, whilst the $\mathrm{Fe}^{2+}$ species content increased to about $73 \%$. There was a need to check whether the increased $\mathrm{Fe}^{2+}$ content was due to the reduction of magnetite by graphite during the milling process. The milling of magnetite using identical milling conditions as stated previously (BPR $40: 1$ ) did not yield a product rich in $\mathrm{Fe}^{2+}$ content, rather a product that was predominantly $\mathrm{Fe}^{3+}$. Hence it could be deduced that carbon was necessary to affect the reduction. The MAS spectra obtained when a BPR of $50: 1$ and beyond (Figures 2(d) and 2(e)) only contained contributions due to the $\mathrm{Fe}^{3+}$ and $\mathrm{Fe}^{2+}$ species with relative contents of 11 and $89 \%$, respectively, with MAS parameters similar to those obtained for the BPR of $40: 1$. The data thus indicated that no further reduction occurred and that all iron oxide was in the form of wüstite. Note that wüstite with up to $13 \%$ of relative content in the form of $\mathrm{Fe}^{3+}$ contribution has been recorded [13] and the $11 \% \mathrm{Fe}^{3+}$ contribution observed in this work is not surprising. XRD probe showed that the magnetite-graphite powder after milling using a BPR beyond $50: 1$ was only composed of wüstite. The fact that no further reduction occurred with increasing BPR beyond $50: 1$ implied that the energy impacted by the balls and bowl on the magnetite-graphite powder was no longer sufficient to reduce the iron oxide any further to form metallic iron and/or iron carbides. In essence, the study showed that by increasing the $\mathrm{BPR}$, whilst keeping the other parameters constant (milling speed and time), magnetite could be selectively reduced to wüstite.

Back scatter electron (BSE) image of ball-milled magnetite is presented in Figure 4. The morphology of the image, Figure 3(a), shows large particle sizes of magnetite and graphite mixture before milling separately in the background. The morphology of the milled mixture, Figure 3(b), shows reduced particle size of magnetite in the mixture as microcrystal. 


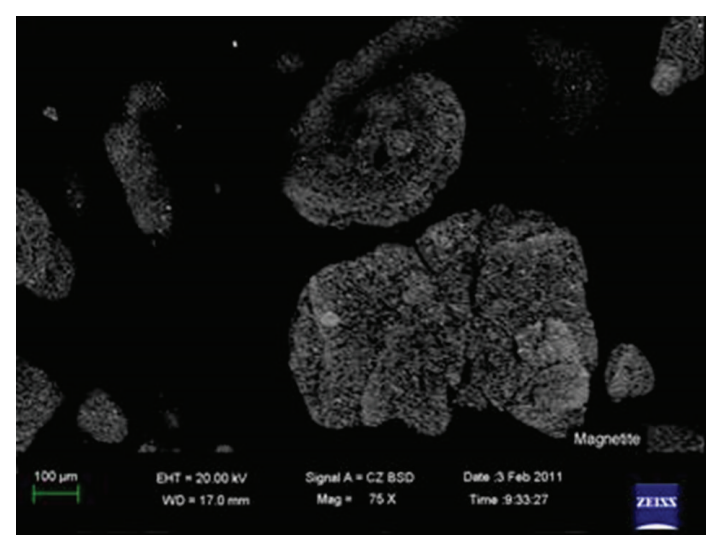

(a)

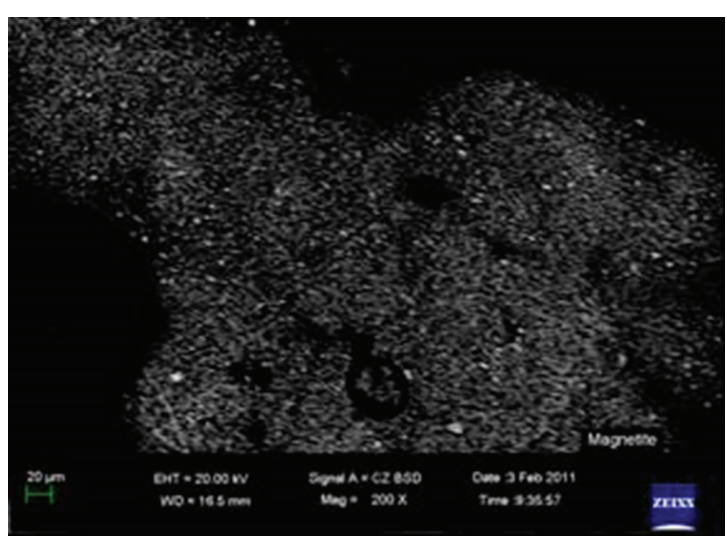

(b)

FIGURE 4: Back Scatter Electron (BSE) images of pure magnetite at different magnifications (a) (75X) and (b) (200X), (a) morphology of particles before milling and (b) morphology of particle after milling for $20 \mathrm{hrs}$.

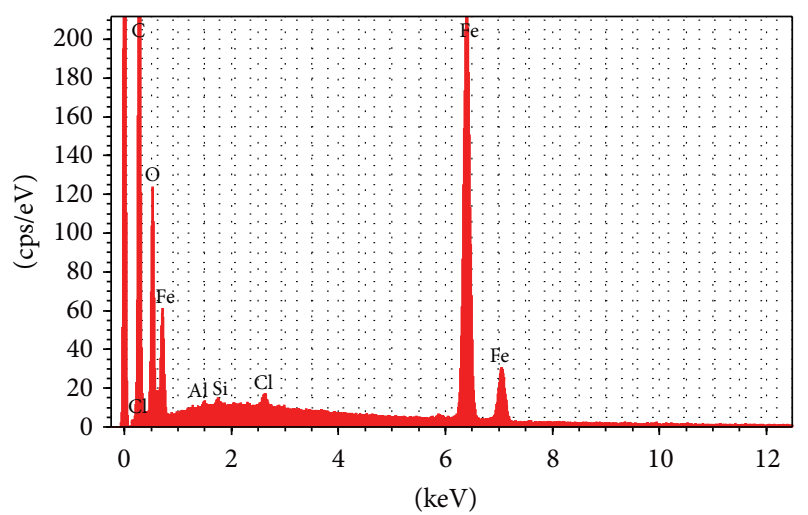

Figure 5: Energy dispersive spectroscopy (EDS) spectra of magnetite and graphite milled for $20 \mathrm{hrs}$.

Figure 5 shows the EDS spectrum of a ball-milled magnetite-graphite mixture. Energy dispersive spectroscopy was employed to identify the elements in the mixture after milling. The spectra show the elements, carbon, oxygen, and iron in large quantity as can be observed from the intensity of their peaks. Other elements observed are chlorine, palladium and gold impurities. The intensity of these elements shows their presence in minute quantities.

Scanning electron micrograph (SEM) of ball-milled magnetite and graphite is presented in Figure 6. Figures 6(a)-6(h) show particle size distributions obtained at various BPRs. The high and low magnification images of $\mathrm{Fe}_{3} \mathrm{O}_{4}$ powder before milling, Figures 6(a) and 6(b), show an agglomeration of fine microcrystals of $\mathrm{Fe}_{3} \mathrm{O}_{4}$, which were predominantly hexagonal in shape. Ball-milled magnetite-graphite mixtures at BPR ratios of $20: 1$ to $100: 1$ are presented in Figures 6(c)6(h). A comparison of Figure 6(b) with Figures 6(f)-6(h), shows a much reduced particle size as a result of milling. At BPR $60: 1$ and beyond, Figures $6(\mathrm{~g})$ and $6(\mathrm{~h})$, no noticeable reductions in particle size were observed despite an increase in BPR. This observation collaborated what was noted using MAS that yielded a constant $\mathrm{Fe}^{3+}$ and $\mathrm{Fe}^{2+}$ contributions that did not vary with BPR beyond $50: 1$. The fact that the milled products were crystalline was confirmed by XRD that detected the presence of crystalline magnetite and/or wüstite phases.

Transmission electron micrograph of ball-milled magnetite and graphite is presented in Figures $7(\mathrm{a})-7(\mathrm{f})$. The images show the magnetite completely fractured into fine particles which are crystalline engulfed in amorphous carbon. The fracture points observed on the magnetite particles are probably reaction points where wüstite was formed as a result of the reduction of magnetite with graphite during the milling process $[14,15]$. Figures $7(\mathrm{c})-7(\mathrm{f})$ show significantly reduced particles as a result of the increased BPR.

\section{Conclusion}

Mechanical alloying of magnetite and graphite at various ball to powder ratios have resulted in the transformation of magnetite to wüstite, selectively. No other iron bearing phase was detected other than the two mentioned previously. The reaction of magnetite and graphite at different milling conditions leads to the formation of $\mathrm{Fe}^{2+}$ and $\mathrm{Fe}^{3+}$ species, the former increasing at the expense of $\mathrm{Fe}_{3} \mathrm{O}_{4} \cdot \mathrm{Fe}_{3} \mathrm{O}_{4}$ completely disappeared after a ball to powder ratio of $50: 1$ and beyond when probed using Mössbauer absorption and X-ray diffraction techniques. The mechanochemistry of the continuous collision between the milling balls induces chemical reaction that resulted in the reduction of magnetite to wüstite. Electron imaging techniques (TEM and SEM) showed continuous reduction of particle size as the BPR was increased. The reduction of magnetite did not continue beyond wüstite suggesting that there was insufficient energy imparted by the balls and bowl to further reduce the iron oxide to metallic iron and/or lead to the formation of carbides. 


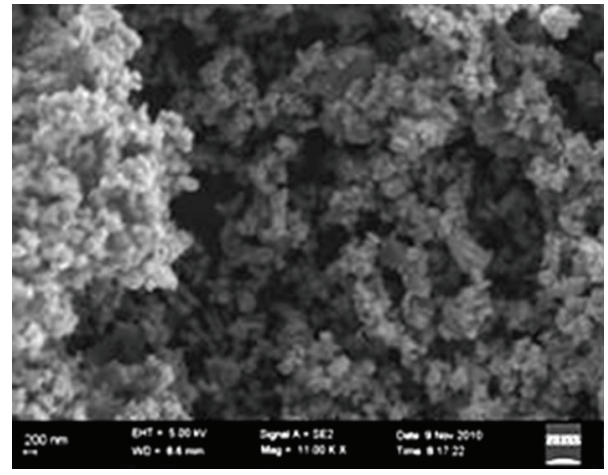

(a)

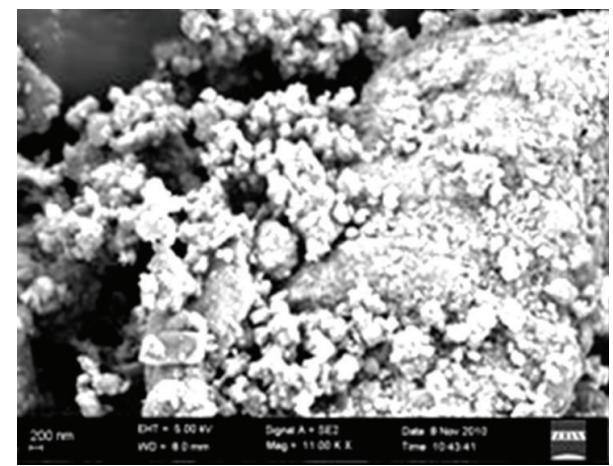

(c)

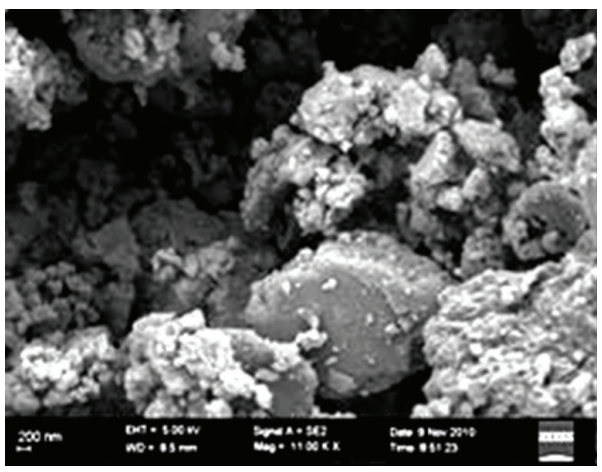

(e)

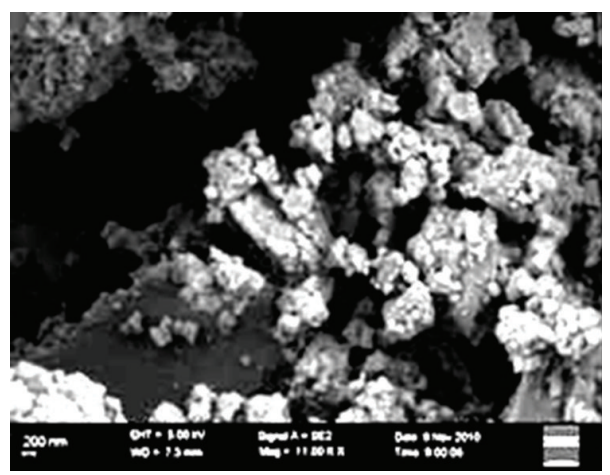

(g)

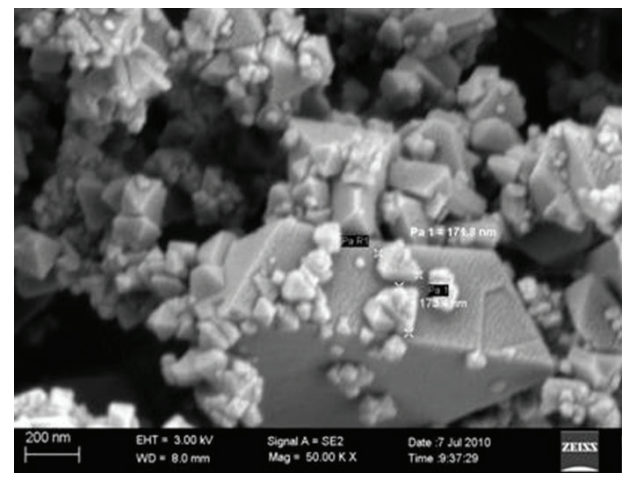

(b)

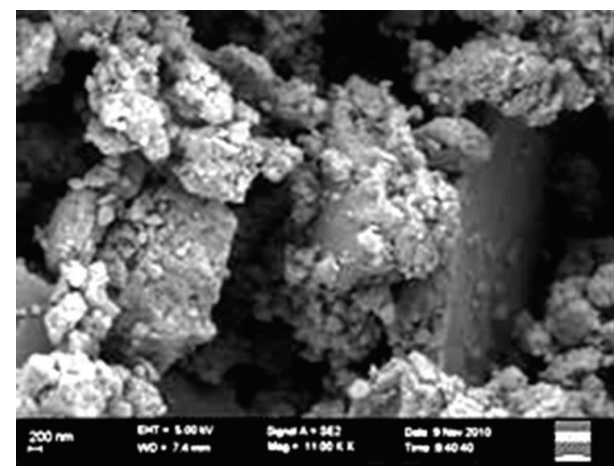

(d)

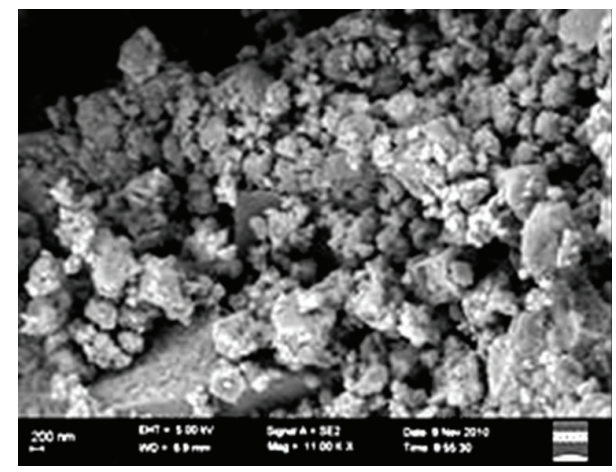

(f)

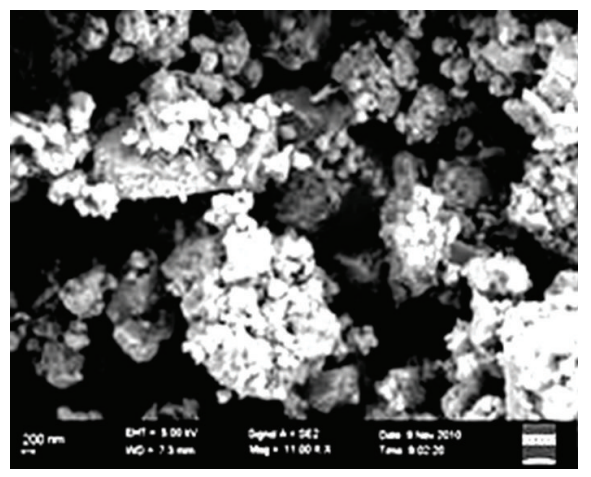

(h)

FIGURE 6: Scanning electron micrograph (SEM) images of (a) $\mathrm{Fe}_{3} \mathrm{O}_{4}$ powder prior to milling at high magnification (50 00K X), (b) $\mathrm{Fe}{ }_{3} \mathrm{O}_{4}$ powder prior to milling at low magnification (11 00K X), (c) $20: 1 \mathrm{BPR}$, (d) $30: 1 \mathrm{BPR}$, (e) $40: 1 \mathrm{BPR}$, (f) $50: 1 \mathrm{BPR}$, (g) $60: 1 \mathrm{BPR}$, (h) $100: 1$ BPR. 


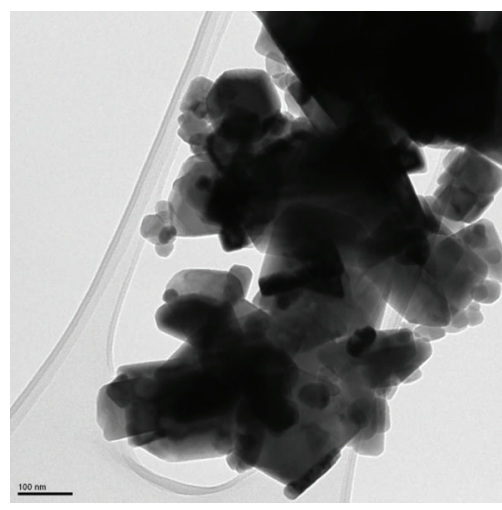

(a)

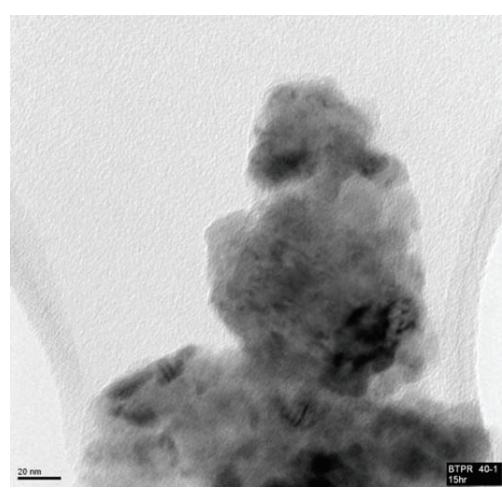

(d)

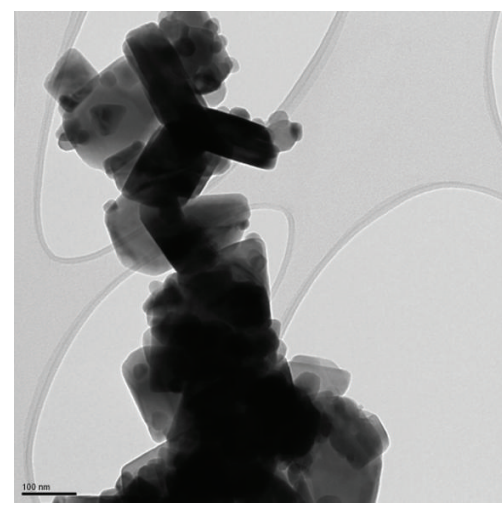

(b)

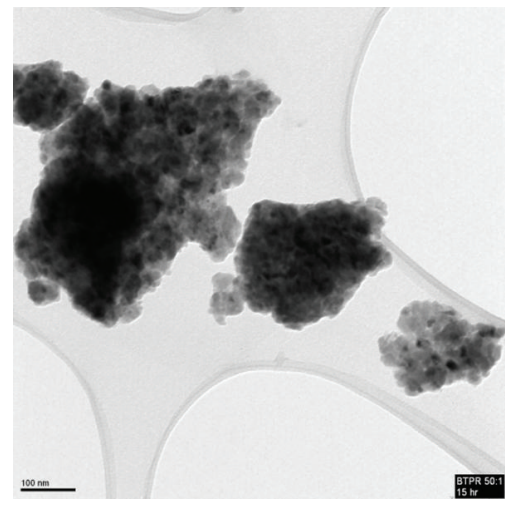

(e)

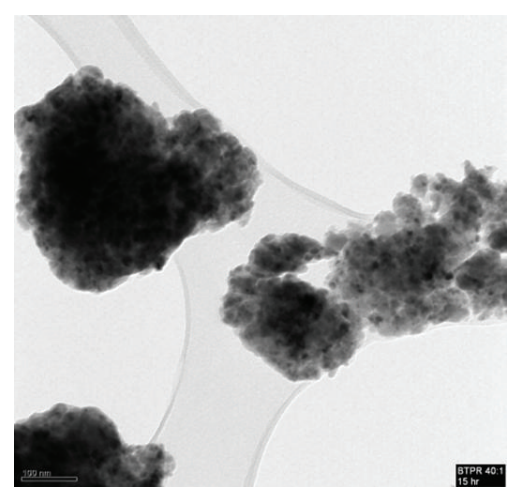

(c)

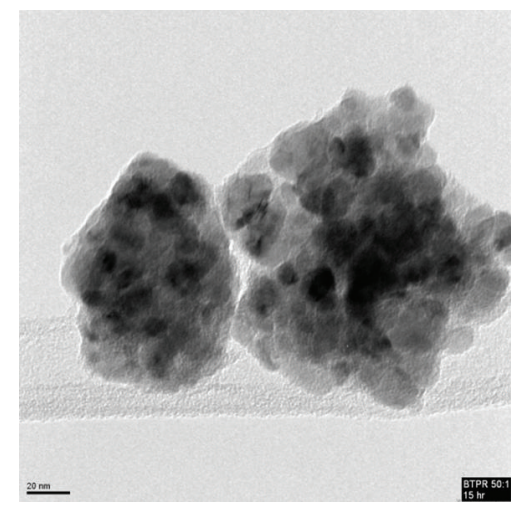

(f)

FIGURE 7: Low magnification transmission electron micrograph (TEM) of pure magnetite (a and b) at 100 nm magnification, (c) TEM image at BPR $40: 1,(100 \mathrm{~nm})$ and (d) $(20 \mathrm{~nm})$. (e) TEM image at BPR $50: 1,(100 \mathrm{~nm})$ and $(\mathrm{f})(20 \mathrm{~nm})$.

\section{Acknowledgments}

This work was supported by Faculty of Applied and Computer Science Research and Publications Committee of Vaal University of Technology, Vanderbijlpark, and the Material Science Department of Sasol, Sasolburg, South Africa.

\section{References}

[1] A. P. Radlinski, A. Calka, B. W. Ninham, and W. A. Kaczmarek, "Application of surface active substances in mechanical alloying," Materials Science and Engineering A, vol. 134, no. C, pp. 1346-1349, 1991.

[2] S. Prakash, "Reduction and sintering of fluxed iron ore pellets-a comprehensive review," Journal of the South African Institute of Mining and Metallurgy, vol. 96, p. 3, 1996.

[3] J. V. Khaki, Y. Kashiwaya, K. Ishii, and H. Suzuki, "Intensive improvement of reduction rate of hematite-graphite mixture by mechanical milling," ISIJ International, vol. 42, no. 1, pp. 13-22, 2002.

[4] V. M. Nadutov, B. N. Mordyuk, G. I. Prokopenko, and I. S. Gavrilenko, "Mössbauer and X-ray studies of Fe-powder mechanically alloyed with C using power ultrasonics," Ultrasonics, vol. 42, no. 1-9, pp. 47-51, 2004.

[5] R. Nowosielski and W. Pilarczyk, "Structure and properties of $\mathrm{Fe}-6.67 \% \mathrm{C}$ alloy obtained by mechanical alloying," Journal of Materials Processing Technology, vol. 162-163, pp. 373-378, 2005.
[6] J. M. Grenèche, M. Hervieuc, A. M. Mercier, and N. Randrianantoandro, "Direct phase transformation from hematite to maghemite during high energy ball milling," Materials Letters, vol. 47, no. 3, pp. 150-158, 2001.

[7] J. V. Khaki, M. R. Aboutalebi, and S. Raygan, "The effect of mechanical milling on the carbothermic reduction of hematite," Mineral Processing and Extractive Metallurgy Review, vol. 25, no. 1, pp. 29-47, 2004.

[8] R. M. Cornell and U. Schwertmann, The Iron Oxides: Structure, Properties, Reactions, Occurrences and Uses, Wiley-VCH, Weinheim, Germany, 2nd edition, 2006.

[9] V. Schünemann and H. Winkler, "Structure and dynamics of biomolecules studied by Mössbauer spectroscopy," Reports on Progress in Physics, vol. 63, no. 3, article 263, 2000.

[10] G. Belozerski, "Mössbauer effect and studies of surface layers," Elsevier, New York, NY, USA, 1993.

[11] B. Rodmacq, "Superparamagnetic properties of small iron hydroxide precipitates in ion exchange membranes," Journal of Physics and Chemistry of Solids, vol. 45, no. 11-12, pp. 1119-1127, 1984.

[12] C. A. McCammon and D. C. Price, "Mössbauer spectra of FexO (x>0.95)," Physics and Chemistry of Minerals, vol. 11, no. 6, pp. 250-254, 1985.

[13] N. N. Greenwood and A. T. Howe, "Mössbauer studies of $\mathrm{Fe}_{1-x}$ O. Part I. The defect structure of quenched samples," Journal of the Chemical Society, Dalton Transactions, pp. 110-116, 1972. 
[14] E. P. Yelsukov, A. L. Ulyanov, and G. A. Dorofeev, "Comparative analysis of mechanisms and kinetics of mechanical alloying in $\mathrm{Fe}-\mathrm{Al}$ and Fe-Si systems," Acta Materialia, vol. 52, no. 14, pp. 4251-4257, 2004.

[15] D. Chen, J. Cai, J. Fang, and Z. Chen, "Preparation of AlMo intermetallic powders by solid-liquid reaction ball milling," Journal of Alloys and Compounds, vol. 485, no. 1-2, pp. L9-L11, 2009. 

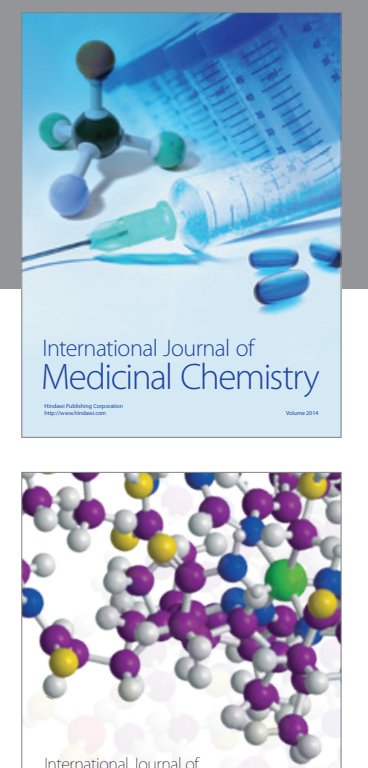

\section{Carbohydrate} Chemistry

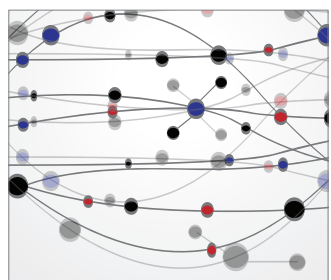

The Scientific World Journal
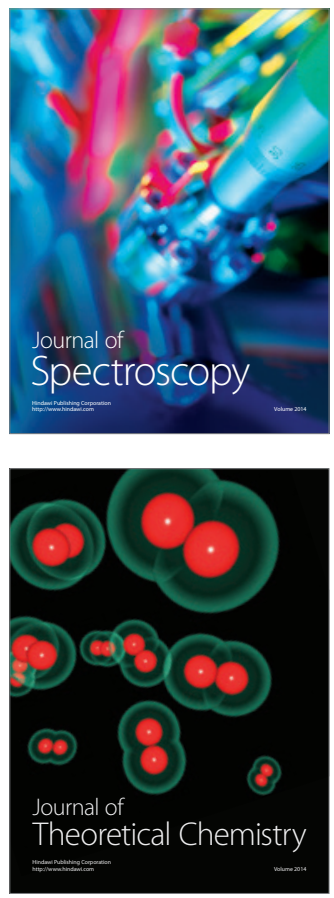
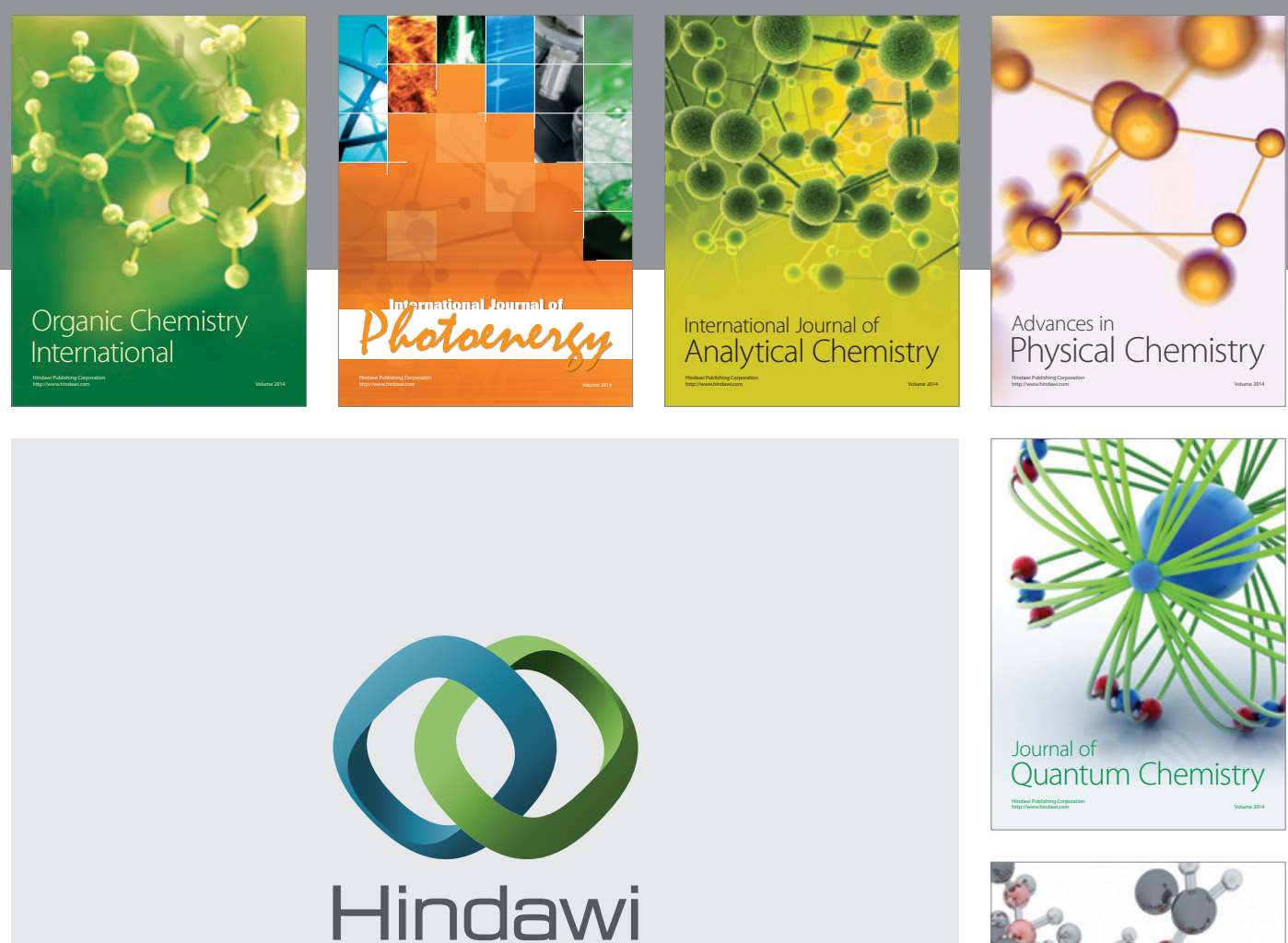

Submit your manuscripts at

http://www.hindawi.com

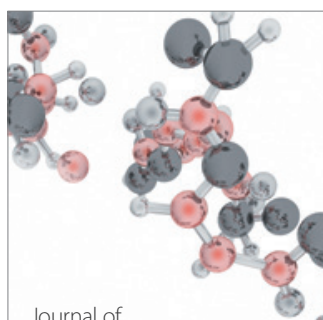

Analytical Methods

in Chemistry

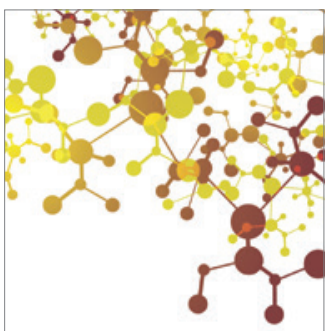

Journal of

Applied Chemistry

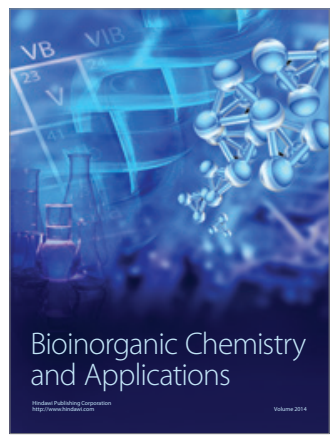

Inorganic Chemistry
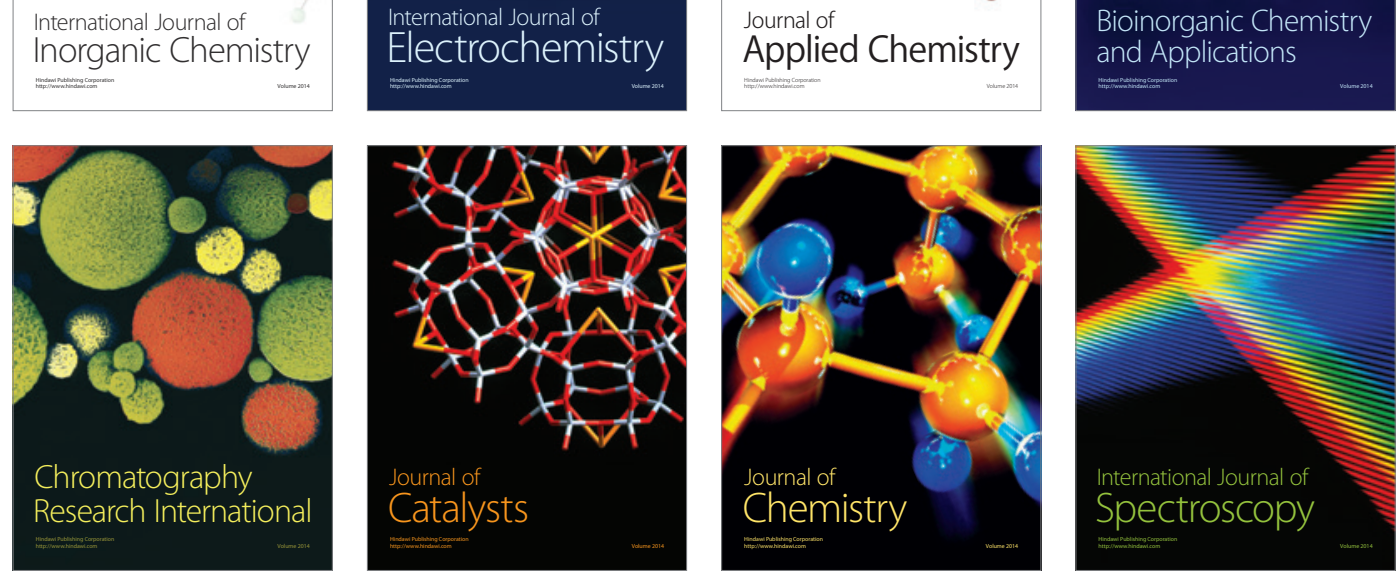